\title{
Description of a new species of the genus Macrosiphum Passerini, 1860 (Hemiptera: Aphidoidea: Aphididae), with a key to the Macrosiphum species occurring in Transcaucasia
}

\author{
Shalva Barjadze \& Nana Gratiashvili
}

\begin{abstract}
Barjadze, S. \& Gratiashvili, N. 2010: Description of a new species of the genus Macrosiphum Passerini, 1860 (Hemiptera: Aphidoidea: Aphididae), with a key to the Macrosiphum species occurring in Transcaucasia. - Entomol. Fennica 21: 43-48.
\end{abstract}
Apterous viviparous females of Macrosiphum dzhibladzeae Barjadze sp. n. liv- ing on Euphorbia macroceras (Euphorbiaceae) are described and illustrated. A key to the apterous viviparous females of Macrosiphum species living on Euphorbia spp. worldwide is given. A previous key for the apterous viviparous females of the Macrosiphum species recorded from Transcaucasia is provided, modified to include the new species.

Sh. Barjadze, LEPL Ilia State University, Entomology and Biocontrol Research Centre, Chavchavadze av.31,0179, Tbilisi, Georgia; E-mail: shalva1980@yahoo.com

N. Gratiashvili, Entomology and Biocontrol Research Centre, LEPL Ilia State University, Chavchavadze av. 31, 0179, Tbilisi, Georgia; E-mail: nanagratiashvili@yahoo.com

Received 20 July 2009, accepted 25 September 2009

\section{Introduction}

The genus Macrosiphum Passerini, 1860 is represented by more than 120 species worldwide (Remaudiere \& Remaudiere 1997, Blackman \& Eastop 2006). Several Macrosiphum species alternate from Rosa to herbaceous secondary hosts, but most species are monoecious holocyclic on shrubs and herbs. The species belonging to this genus are distributed in North America, Europe and Asia (Blackman \& Eastop 2006).

Up to now, nine species, i.e. Macrosiphum cholodkovskyi (Mordvilko, 1909), M. euphorbiae (Thomas, 1878), M. funestum (Macchiati, 1885), M. gei (Koch, 1855), M. hellebori Theobald \& Walton, 1923, M. melampyri Mordvilko,
1919, M. rosae (Linnaeus, 1758), M. symphyti Barjadze \& Chakvetadze, 2008 and M. tinctum (Walker, 1849) have been recorded in Transcaucasia (Uvarov 1918, Arutiunian 1967, Alieva 1980, Barjadze \& Kvavadze 2005, Barjadze \& Chakvetadze 2008, Barjadze et al. 2009). Four species of the genus Macrosiphum, M. amygdaloides Theobald, 1925, M. euphorbiae (Thomas, 1878), M. inexpectatum Leclant, 1974 and M. meixneri Börner, 1950, are known from Euphorbia worldwide (Blackman \& Eastop 2006).

Restudy of the aphid specimens of the genus Macrosiphum collected by Dr. A. Dzhibladze on Euphorbia macroceras Fisch. \& C.A.Mey. in 1957 led us to describe here a new species. During the description process, three additional 
Table 1. Biometric data of Macrosiphum dzhibladzeae sp. n. $(n=10)$ (holotype in parentheses). Measurements are given in $\mathrm{mm}$.

\begin{tabular}{|c|c|}
\hline Body & $3.11-3.85(3.73)$ \\
\hline Antenna & $3.62-4.70(4.70)$ \\
\hline URS & $0.124-0.152(0.133)$ \\
\hline SIPH & $0.92-1.19(1.09)$ \\
\hline Cauda & $0.50-0.56(0.56)$ \\
\hline HTII & $0.190-0.209(0.200)$ \\
\hline ANT III & $0.97-1.17(1.12)$ \\
\hline ANT IV & $0.68-0.92(0.90)$ \\
\hline ANT V & $0.62-0.83(0.76)$ \\
\hline ANT VIb & $0.162-0.190(0.181)$ \\
\hline ANT VI PT & $0.93-1.26(1.01)$ \\
\hline Hind femur & $1.40-1.71(1.60)$ \\
\hline Hind tibia & $2.60-3.14(3.05)$ \\
\hline No. of sec. rhin. on ANT III & $2-6(6)$ \\
\hline $\begin{array}{l}\text { No. of setae on the inner } \\
\text { side ventrally of each } \\
\text { antennal tubercle }\end{array}$ & $2-3(3)$ \\
\hline $\begin{array}{l}\text { No. of accessory setae } \\
\text { on URS }\end{array}$ & $7-10(9)$ \\
\hline $\begin{array}{l}\text { No. of dorsal setae } \\
\text { on ABD TERG VIII }\end{array}$ & $6-8(7)$ \\
\hline $\begin{array}{l}\text { No. of setae } \\
\text { on subgenital plate: }\end{array}$ & \\
\hline discal & 6-9 (9) \\
\hline $\begin{array}{l}\text { marginal } \\
\text { No. of caudal setae }\end{array}$ & $\begin{array}{l}16-18(18) \\
15-19(18)\end{array}$ \\
\hline $\begin{array}{l}\text { Length of longest setae } \\
\text { on ABD TERG III }\end{array}$ & $38-67 \mu \mathrm{m}(57)$ \\
\hline
\end{tabular}

Abbreviations: BL: length of body; ANT I: antennal segment I; ANT II: antennal segment II; ANT III: antennal segment III; ANT IV: antennal segment IV; ANT V: antennal segment V; ANT VIb: the base of antennal segment VI; ANT III BD: basal diameter of antennal segment III; ANT VI PT: processus terminalis; sec. rhin.: secondary rhinaria; URS: ultimate rostral segment; HTII: second segment of hind tarsus; SIPH: siphunculus; ABD TERG III: abdominal tergite III; ABD TERG VIII: abdominal tergite VIII.

apterous viviparous females of the new species were collected in Samtskhe-Javakheti region (Southern Georgia) in 2009.

\section{Materials and methods}

Seven apterous viviparous females collected by Alexandra Dzhibladze and three additional ones by Shalva Barjadze were studied. The specimens were studied using a PHENIX-H-200 microscope and morphological characters were measured by microscope ocular-micrometer. Measurements are recorded mainly in millimeters and listed as ranges. Measurements of morphological

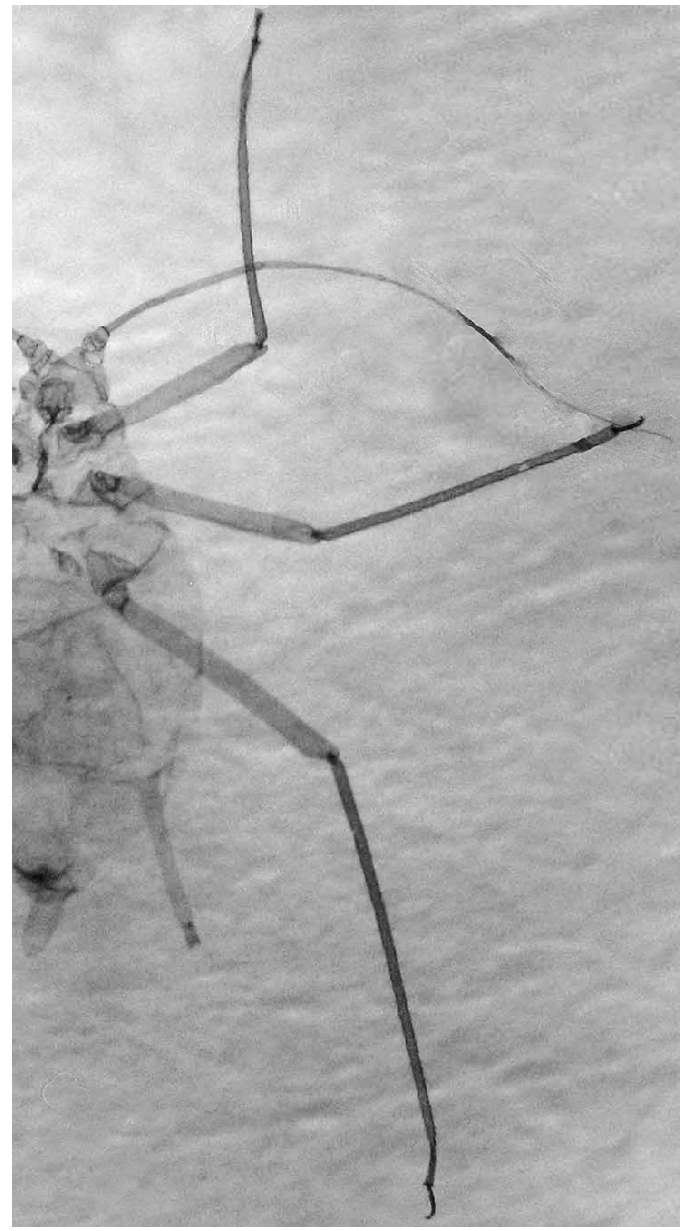

Fig. 1. Body of apterous viviparous female of Macrosiphum dzhibladzeae sp. n. (paratype No. 2).

characters and ratios given in this paper are according to Holman (1962).

The holotype and paratypes of the new species are deposited in the Institute of Zoology of Georgia (IZG). Abbreviations used in the key and description are explained in Table 1.

\section{Description of Macrosiphum dzhibladzeae Barjadze sp. $n$. (Table 1, Figs. 1, 2)}

\subsection{Material examined}

Type material. Holotype: apterous viviparous female, No. 1957-0039a, Georgia: Racha, Lechkhumi, Kvemo Svaneti region, Lentekhi district, 
Fig. 2. Body parts of apterous viviparous female of Macrosiphum dzhibladzeae sp. n. (a-c and e: paratype No. 1, d: holotype). - a. Head, with antennal segments I and II. - b. Antennal segment III. - c. Ultimate rostral segment. -d. Subgenital plate. - e. Cauda.
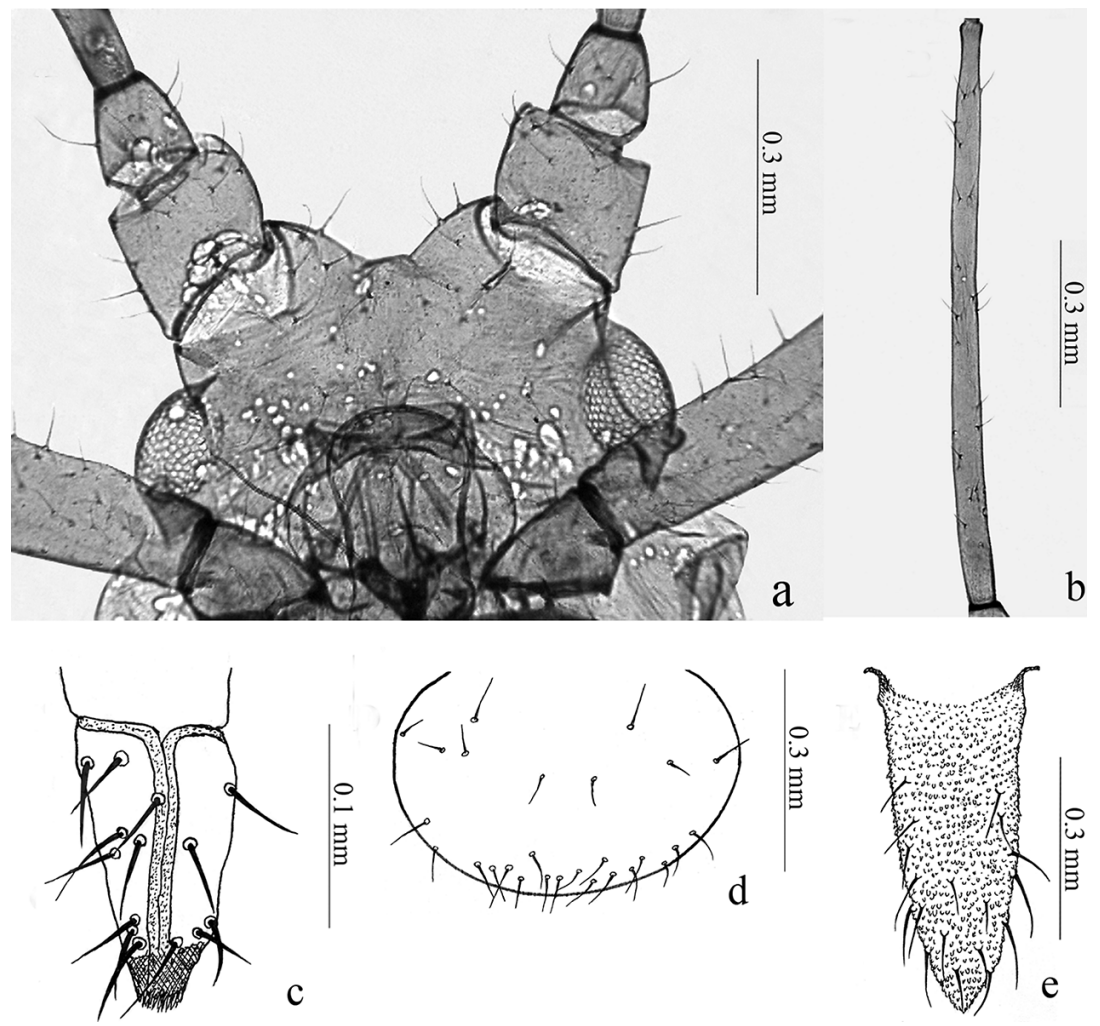

Near to Koruldashi village, N42 ${ }^{\circ} 55^{\prime} 06^{\prime \prime}$; E4308'38", 2,100 m a.s.1., 29.VII.1957, on Euphorbia macroceras, leg. A. Dzhibladze (IZG). Holotype labeled on slide.

Paratypes: 6 apterous viviparous females, No. 1957-0039b, 1957-0039c and 1957-0039d on 3 slides, with the same locality and date as the holotype.

Additional specimens: 3 apterous viviparous females, No. 2009-303 on 3 slides, Georgia: Samtskhe-Javakheti region, Adigeni district, N41 ${ }^{\circ} 49^{\prime} 15.1$ " ; E42 50'58.6", 2,013 m a.s.1., 14.VII.2009, on Euphorbia macroceras, leg. Sh. Barjadze (IZG).

\subsection{Apterous viviparous females}

Color in living specimens: body yellow with median green strip on thorax and abdomen; ANT I, II, III, IV and ANT V yellow except for apices; apices of ANT V and whole ANT VI dark, tarsus dark; SIPH yellow, cauda green, Color in macerated specimens: body pale; ANT I, II, III, IV and
ANT V pale except for apices; apices of ANT V and ANT VI brown; rostrum pale; URS brown towards apical part; femur smoky; tibia light brown; tarsus brown; SIPH smoky; Apical reticulated area of the SIPH often dusky; cauda pale.

Morphological characters (ratios, as ranges based on all the 10 specimens, holotype in parentheses): Body spindle shaped (Fig. 1). Head smooth. Antennal tubercles well developed (Fig. 2a), diverging. Cephalic setae rather acute, $1.42-$ 1.67 (1.50) times longer than ANT III BD. Antennae 1.10-1.40 (1.15) times longer than BL. ANT III (Fig. 2b) nearly smooth. ANT III 0.82-1.10 (1.04) times as long as SIPH and 0.30-0.33 (0.30) times as long as BL. ANT IV, ANT V, ANT VIb 0.67-0.81 (0.80), 0.61-0.82 (0.68), 0.16-0.20 (0.16) times as long as ANT III, respectively. ANT VI PT 0.90-1.28 (0.90) times longer than ANT III and 5.57-7.16 (5.57) times longer than ANT VIb. ANT V 3.85-4.36 (4.21) times longer than ANT VIb. Antennal setae acute, the longest ones $0.81-1.00(0.82)$ times as long as ANT III BD. Sec. rhin. arranged in one line on basal 0.20 $0.28(0.28)$ part of ANT III. URS (Fig. 2c) blunt 
Table 2. Comparison of Macrosiphum dzhibladzeae sp. n. with M. laseri Holman, 1962 Measurements are given in $\mathrm{mm}$. Abbreviations are explained in Table 1.

\begin{tabular}{lll}
\hline & $\begin{array}{l}\text { Macrosiphum } \\
\text { dzhibladzeae sp. n. (10) }\end{array}$ & M. laseri (10) \\
\hline $\begin{array}{l}\text { No. of setae on each antennal } \\
\quad \text { tubercle ventrally }\end{array}$ & $2-3$ & \\
No. of caudal setae & $15-19$ & 4 \\
No. of sec. rhin. on ANT III & $2-6$ & $12-14$ \\
Hind femur/BL & $0.42-0.53$ & $6-14$ \\
Hind tibia/BL & $0.79-1.01$ & $0.35-0.43$ \\
Host plants & Euphorbia macroceras & $0.67-0.75$ \\
\hline
\end{tabular}

or acute, $0.65-0.76(0.65)$ times as long as HTII and $0.68-0.84(0.73)$ times as long as ANT VIb. URS does not reach to hind coxa. Total length of rostrum $0.69-0.87(0.81)$ times as long as ANT III. Legs long, hind femur and hind tibia 0.42 $0.53(0.43)$ and $0.79-1.01(0.82)$ times as long as $\mathrm{BL}$, respectively. Ventral setae on the trochanters of hind legs $0.57-0.67(0.64)$ times as long as the trochanto-femoral suture. Chaetotaxy of the first tarsal joints: 3:3:3. Tergum without any distinct sclerotization. Dorsal setae acute. Longest setae on ABD TERG VIII 1.29-1.57 (1.50) times longer than ANT III BD. SIPH cylindrical, smooth, with enlarged base and 0.28-0.38 (0.29) times longer than BL. Apical reticulated area covers 0.17-0.20 (0.20) part of the SIPH length, constricted. Flange small. Subgenital plate (Fig. 2d) widely oval or quadrangular and sclerotized. Cauda (Fig. 2e) elongated triangular and not or slightly constricted at basal 1/3, 1.93-2.3 (1.97) times as long as its basal width and 0.44-0.54 (0.52) times as long as SIPH. Other characteristics are given in Table 1.

Fundatries, alate viviparous females, males and oviparae: unknown.

Life cycle: The life cycle is unknown; it lives in dense colonies on the stems and undersides of leaves of Euphorbia macroceras Fisch. \& C. A. Mey. (data on the labels of the slides), which is endemic to the Caucasus.

Etymology: The specific name is chosen in honour of the Georgian aphidologist, Alexandra Dzhibladze, who collected this species.

\section{Comparison of Macrosiphum dzhibladzeae sp. $\mathrm{n}$. with other species}

Comparisons of M. dzhibladzeae sp. n. with morphologically closely related species $M$. laseri and Euphorbia feeding Macrosiphum species are given in the Tables 2 and 3.

\section{Key to the apterous viviparous females of the Macrosiphum Passerini species feeding on Euphorbia spp. worldwide}

The key presented below was adopted from Blackman and Eastop (2006) by including Macrosiphum species feeding on Euphorbia spp. worldwide and by adding M. dzhibladzeae. Abbreviations used in the key are explained in Table 1.

1. Total length of rostrum $0.89-1.09$ times ANT III M. inexpectatum Leclant, 1974

- Total length of rostrum 0.57-0.87 times ANT III

2. Longest setae on ABD TERG III are 21$37 \mu \mathrm{m}$. URS 0.80-1.10 times ANT VIb

M. euphorbiae (Thomas, 1878)

- Longest setae on ABD TERG III are 32$72 \mu \mathrm{m}$. URS $0.45-0.84$ times ANT VIb. 3

3. URS 0.45-0.62 times ANT VIb. ANT III with 6-20 sec.rhin M. meixneri Börner, 1950

- URS 0.68-0.84 times ANT VIb. ANT III with $1-10$ sec. rhin

4

4. URS 0.79-0.91 times HTII. The apex of the femur always dark Theobald, 1925
M. amygdaloides 
Table 3. Comparison of Macrosiphum dzhibladzeae sp. n. with Euphorbia feeding Macrosiphum species. Numbers of measured specimens are given in parentheses after each species. Measurements are given in $\mathrm{mm}$. Abbreviations are explained in Table 1.

\begin{tabular}{lll}
\hline & M. dzhibladzeae (10) & M. amygdaloides (6) \\
\hline $\begin{array}{l}\text { URS/HTII } \\
\text { Color of femur }\end{array}$ & $\begin{array}{l}0.65-0.76 \\
\text { the apex always pale }\end{array}$ & $\begin{array}{l}0.79-0.91 \\
\text { the apex always dark }\end{array}$ \\
\hline & M. dzhibladzeae (10) & M. euphorbiae (23) \\
\hline URS/HTII & $0.65-0.76$ & $0.83-1.08$ \\
URS/ANT VIb & $0.68-0.84$ & $0.8-1.1$ \\
Length of setae on ABD TERG III & $38-67 \mu \mathrm{m}$ & $21-37 \mu \mathrm{m}$ \\
\hline & $M$. dzhibladzeae (10) & M. inexpectatum (6) \\
\hline Rostrum/ANT III & $0.69-0.87$ & $0.89-1.09$ \\
No. of caudal setae & $15-19$ & $9-10$ \\
\hline & $M$. dzhibladzeae (10) & M. meixneri (3) \\
\hline URS/ANT VIb & $0.68-0.84$ & $\begin{array}{l}0.45-0.62 \\
0.24-0.29 \\
\text { SIPH/BL }\end{array}$ \\
No. of sec. rhin. on ANT III & $0.28-0.38$ & $2-7$ \\
No. of discal setae on subgenital plate & $6-9$ & \\
\hline
\end{tabular}

- URS 0.65-0.76 times HTII. The apex of the femur always pale M.dzhibladzeae sp.n.

\section{Key to the apterous viviparous females of the genus Macrosiphum Passerini species known from Transcaucasia}

Abbreviations used in the key are explained in Table 1.

1. URS with 13 or more accessory setae 2

- URS with less than 13 accessory setae 3

2. SIPH dark. ABD TERG VIII with 6-8 setae. Subgenital plate with 2-4 and 16-23 discal and marginal setae, respectively. On Rubus spp.

M. funestum (Macchiati, 1885)

- SIPH pale. ABD TERG VIII with 7-12 setae. Subgenital plate with 4-10 and 13-18 discal and marginal setae, respectively. On Symphytum asperum

M. symphyti Barjadze \& Chakvetadze, 2008

3. Longest setae on ABD TERG III are 21$37 \mu \mathrm{m}$
- Longest setae on ABD TERG III are more than $37 \mu \mathrm{m}$

5

4. URS 0.98-1.15 times HT II. Dark apical sections of tibiae often markedly swollen, to 1.5 or more times the least more proximal diameter. Posterior part of head (between eyes) usually with one or a pair of small spinal tubercles, and similar, often paired, tubercles common also on ABD TERG VIII, or VII and VIII. On Epilobium parviflorum

M. tinctum (Walker, 1849)

- URS 0.83-1.08 times HT II. Apices of tibiae not so distinctly swollen. Spinal tubercles absent or only irregularly present, rarely on head and rarely paired on ABD TERG VII-VIII. On Solanum tuberosum. Polyphagous elsewhere M. euphorbiae (Thomas, 1878)

5. SIPH completely black. Frons and ANT I and II also dark. ANT III with 10-36 sec. rhin. On Cephalaria gigantea, Eucalyptus viminalis, Rosa damascene var. trigintipetala, Rosa spp., Scabiosa caucasica, S. ochroleuca, Valeriana tiliifolia

M. rosae (Linnaeus, 1758) 
- SIPH smoky or not completely black. Frons and ANT I and II not dark. ANT III with 1-10 sec. rhin. On other plants

6. SIPH smoky. The apex of the femur always pale. On Euphorbia macroceras

M. dzhibladzeae sp.n.

- SIPH pale at the base. The apex of the femur always dark. On other plants

7. Subgenital plate with 2 discal setae. URS $0.70-0.80$ times ANT VI $b$ and $0.8-1.0$ times HT II. On Digitalis ferruginea

M. melampyri Mordvilko, 1919

- Subgenital plate with 2-12 discal setae. URS $0.60-0.95$ times ANT VIb and 0.80-1.18 times HT II. On other plants

8

8. Subgenital plate with $2-5$ discal setae. ANT VI base 0.13-0.20 ANT III. On Valeriana alliariifolia

M. cholodkovskyi (Mordvilko, 1909)

- Subgenital plate with 4-12 discal setae. ANT VI b 0.15-0.28 ANT III. On Chaerophyllum or Helleborus

9. ANT VI b 0.15-0.18 ANT III. ANT VI PT 6.4-7.7 ANT VIb. On Helleborus caucasicus

M. hellebori Theobald \& Walton, 1923

- ANT VI base 0.20-0.28 ANT III. ANT VI PT 4.5-6.0 ANT VI b. On Chaerophyllum aureum M. gei (Koch, 1855)

Acknowledgements. We are grateful to the colleagues who helped us during the preparation of this paper, providing material on loan and giving valuable comments on our manuscript: Drs. R. L. Blackman and V. Eastop (The Natural History Museum, London, UK), Juan M. Nieto Nafria (Departamento de Biodiversidady Gestion Ambiental,
Universidad de Leon, Spain), Gary Miller (Plants Science Institute, Beltsville, USA). We gratefully acknowledge the technical support by Dr. O. Gorgadze (Institute of Zoology of Georgia, Tbilisi, Georgia).

\section{References}

Alieva, Z. M. 1980: (Aphids of the Absheron peninsula.) - Baku, Institute of Zoology of Azerbaijan, Doctoral dissertation. 234 pp. [In Russian.]

Arutiunian, G. A. 1967: (Aphid insect pest on ornamental plants in some towns in Armenia.) - Biological Journal of Armenia 20: 61-67 [In Russian.]

Barjadze, Sh. \& Kvavadze, E. 2005: Host plants and nutrition specialization of aphids (Hemiptera: Sternorrhyncha) inhabitated in the riv. Dzama, Tana and Tedzami ravines. - Proceedings of the Georgian Academy of Sciences. Biological series B, 3: 85-89.

Barjadze, Sh. \& Chakvetadze, N. 2008: A new species of the genus Macrosiphum (Hemiptera: Aphididae) living on Symphytum asperum (Boraginaceae) from Georgia. - Annales Zoologici 58: 551-556.

Barjadze, Sh. Z., Bakhtadze, N. G., Bakhtadze, G. I., Kintsurashvili, N. T., Chakvetadze, N. L. \& Zhukovskaya, N. A. 2009: Contribution to the aphid fauna (Hemiptera: Aphidoidea) of Racha-Lechkhumi floristic region (Western Georgia). - Zoosystematica Rossica 18: 54-58.

Blackman, R. L. \& Eastop, V. F. 2006: Aphids on the world's herbaceous plants and shrubs. - John Wiley \& Sons, London. 1439 pp.

Holman, J. 1962: Three new species of the subfam. Dactynotinae from the Crimea (Homoptera). - Acta Societatis Entomologicae Čechosloveniae 59: 28-37.

Remaudiere, G. \& Remaudiere, M. 1997: Catalogue des Aphididae du Monde. — INRA, Paris. 473 pp.

Uvarov, B. P. 1918: (Review of insect pests of crops of Tbilisi and Yerevan provinces.) — Georgian creative work of printing, Tbilisi. 58 pp. [In Russian.] 